\title{
6. Can the Internet Revolutionise Finance in China?
}

\author{
Yiping Huang, Yan Shen, Jingyi Wang and Feng Guo
}

\section{Introduction}

The Chinese term for 'internet finance' was coined by Ping Xie and Chuanwei Zou (2012) at the 2012 Annual Conference of the China Finance 40 Forum. It now enjoys a place in public discourse alongside such phrases as 'digital finance' and 'fintech', which are often used outside China. The context for the use of 'internet finance', however, is somewhat richer, as internet finance can refer to both information technology (IT) companies providing financial services, such as WeChatPay, and financial institutions applying IT to their more traditional services, such as the e-ICBC service of the Industrial and Commercial Bank of China (ICBC). Narrow definitions of internet finance nonetheless embrace a wide range of activities, including third-party payment, online lending, direct sales of funds, crowd-funding, online insurance and banking and digital money. Our discussion in this chapter focuses on the potential of internet finance in China.

Internet finance has been operating in China for more than 10 years. AliPay was launched in 2004 and CreditEase was established in 2005. Most people, however, regard the launch of Yu'ebao, an online sales platform for money market funds established by Alibaba's Ant Financial Services in June 2013, as the point from which the recent explosive development of internet finance in China began. Public sentiment towards internet finance has moved the full gamut from fever pitch to fear. Extreme feelings - from exuberance to pessimism - are common among the public and in the market. Often such sentiments do not represent the true picture. As scholars, we have a responsibility to study the innovation, revealing the key risks and recommending sensible policies regardless of market sentiment.

This chapter attempts to shed some light on the central question of whether China's new internet finance economy reflects real innovation or a superficial bubble. We first describe recent developments in internet finance using some of the findings of the newly constructed Peking University Internet Finance Development Index (IFDI). We then try to identify the key factors contributing to the surge in internet finance, by drawing lessons from China's past financial reform. We also attempt to assess potential risks associated with internet finance and discuss implications for the guiding regulatory framework through a case study of peer-to-peer (P2P) lending platforms. 
Our main arguments can be summarised as follows. The rise of internet finance in China has been triggered by at least three factors. First, repressive financial policy produces an undersupply of financial services, especially for small and medium-sized enterprises (SMEs) and low-income households. This leaves a hole in the financial market. Second, regulator tolerance has provided space for internet finance to emerge and grow. And, third, IT tools, especially mobile terminals and big data analysis, increasingly offer effective ways for internet finance to increase its efficiency and control financial risk. In short, there are many legitimate explanations for the emergence of internet finance.

Some critiques express fear that internet finance is an attempt to rewrite financial laws rather than merely a utilisation of new technological tools to facilitate existing financial transactions. For example, Mingshun Li, chief executive officer of an internet finance company in China, announced that his enterprise would start a revolution as it can safely lend money to every part of the heating market. ${ }^{1}$ Information technologies are in fact likely to be widely applied to all types of financial transactions, but only some types of internet finance will survive. These will be those that effectively solve real problems for financial transactions - for example, Zhima Credit, a credit-collecting company launched by Ant Financial that has set up an individual credit evaluation system.

We believe that far from being a threat to the traditional finance industry, internet finance will increasingly become an effective tool with which to promote inclusive finance and thus also increase the size and reach of financial services. Internet finance, that is, can play a supplementary role, enhancing traditional financial transactions and extending financial services to areas that traditional finance has not yet embraced. For example, internet finance may facilitate inclusive finance by providing market-based services to financially underserviced SMEs and low-income households. The most successful cases of this to date involve taking advantage of either large numbers of mobile terminals, such as AliPay, or analyses of available data, such as WeBank's Weilidai. Internet finance itself also faces challenges and risks, including serious investment bubbles and widespread Ponzi schemes. If uncontrolled, these risks could destroy the entire industry. In response, some local governments have already prohibited registration of new P2P platforms.

Healthy development of internet finance requires at least three necessary conditions. The first is good infrastructure, including big data, integrated credit information and effective market discipline. The second is a troupe of qualified financial professionals. And the third is a regulatory framework that strikes the balance between controlling risk and encouraging innovation.

1 Available from: economy.gmw.cn/2016-05/13/content_20091004.htm. 


\section{Recent developments}

Internet finance is a relatively new development even though its impact has already been felt in many areas and at least several well-known institutions have emerged. The most widely used internet finance service is probably third-party payments. In China, this market is already dominated by two players, AliPay and WeChatPay, which at the end of 2015 had more than 270 million and 200 million active users respectively. Another active area is online lending, which includes both $\mathrm{P} 2 \mathrm{P}$ platforms and online micro credit. CreditEase is ranked as the largest P2P firm in the world, although it prefers to call itself a marketplace firm, because its borrowers include SMEs as well as individuals. Its platform Yirendai listed on the New York Stock Exchange at the end of 2015. That same year, P2P lending reached RMBl trillion. Ant Financial's Mayiweidai and WeBank's Weilidai are also both rapidly expanding online lending businesses.

In this chapter, we introduce some outstanding types of internet finance. First, internet payments are the most well-developed business, with a history going back more than 10 years. Founded by the Alibaba group, AliPay is an online payment services provider that allows individuals and businesses to make secure online payments. AliPay is used primarily by buyers and sellers engaging in e-commerce transactions, and it is also the main payment method on its sister site Taobao. Second, money market funds or online direct investment funds are investment funds sold directly through a platform of internet companies. Such companies act as no more than an intermediary and the money is actually handled by traditional, heavily regulated funds. The most famous online direct investment fund in China is Yu'ebao, launched by Alibaba in 2013. Third, P2P has been one of the most explosive sectors of internet finance since 2014. There are more than 4,000 platforms in China, attracting nearly three million people to lend their money (Huang et al. 2016). There are also famous P2P platforms outside China, such as Lending Club, Prosper and OnDeck.

Online direct investment fund sales are also quite active, with the best-known such product being Yu'ebao. Tianhong Investment Fund, which manages a money market fund for Yu'ebao, had assets worth RMB500 billion within a year of Yu'ebao's launch, becoming the largest investment fund in China. The previous top-ranked firm, the China Investment Fund, took 17 years to reach the same asset size. Following the sharp decline of interbank market rates in 2014, Ant Financial launched another platform, Zhaocaibao, with the aim of selling wealth management products and investment funds. At the end of 2015, the market size for such investment products reached an estimated RMB1 trillion. ${ }^{2}$ There are also a number of crowd-funding platforms, among which the

2 Data source: wdzj.com (one of the leading P2P lending information websites in China). 
most prominent are Angel Crunch and Demo Hour. Two online banks, WeBank and MyBank, also received their operating licences in 2015, but growth has been limited by regulatory restrictions on the remote opening of bank accounts in China.

To advance systematic measurement of China's internet finance industry, Peking University's Institute of Internet Finance developed the Peking University IFDI, with assistance from Ant Financial Services. The IFDI, which was launched in December 2015, is a monthly measure that begins in January 2014 and is disaggregated across 31 provinces and 335 prefecture-level cities. It comprises a weight of six subindices for the main business categories of internet finance: investment (10 per cent), money market funds (25 per cent), insurance (15 per cent), payment ( 30 per cent), lending ( 15 per cent) and credit rating ( 5 per cent) (Guo et al. 2016).

The six indices correspond to the business categories that are commonly taken as the principles used for index calculation-namely, representativeness, feasibility, divisibility and expandability. The January 2014 nationwide index is normalised to 100 and indices of other times or districts are based on that. An increase in the index means development in that district or business category (Guo et al. 2016).

The results indicate that between January 2014 and December 2015, the nationwide IFDI increased from 100 to 386 (Figure 6.1). The average monthon-month growth rate was 5.8 per cent in 2014 and increased to 6.7 per cent in 2015. Among the six business categories, payments and money market funds, represented by AliPay and Yu' ebao respectively, enjoyed relatively slow growth, probably as they were already more mature than the other firms. The boom in P2P lending from 2014 is driven mainly by the investment subindex (Figure 6.1). Insurance fluctuation implies that it was more limited and heavily influenced by e-commerce sales.

There was also very wide interprovincial variation in terms of both levels of internet finance activities and their pace of growth (Figure 6.2). Specifically, the activity levels of seven relatively more developed provinces, as measured by gross domestic product (GDP) per capita, exceeded the national average. The provinces with relatively low levels of internet finance activities, however, were the ones that showed modestly faster growth rates in both 2014 and 2015, suggesting a possible trend of convergence over time. 


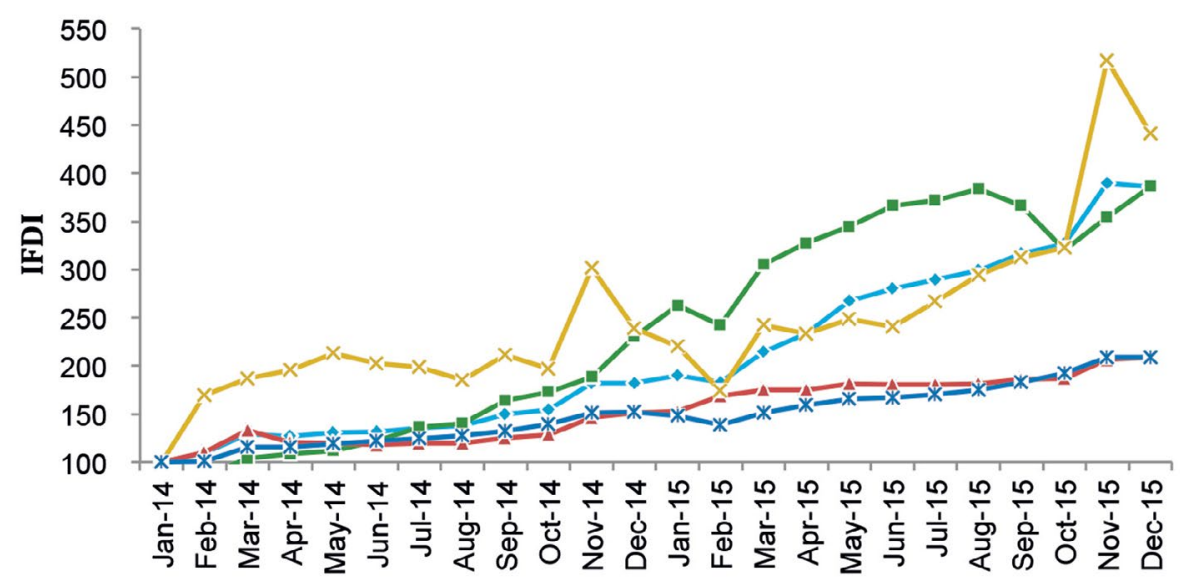

$-\bullet-I F D I \quad-\square-$ Investment $\quad-\wedge$ Money market fund $\quad-\times-$ Insurance $\quad-*-$ Payment

Figure 6.1 IFDI: Aggregated and by subsector, 2014-15

Source: Guo et al. (2016).

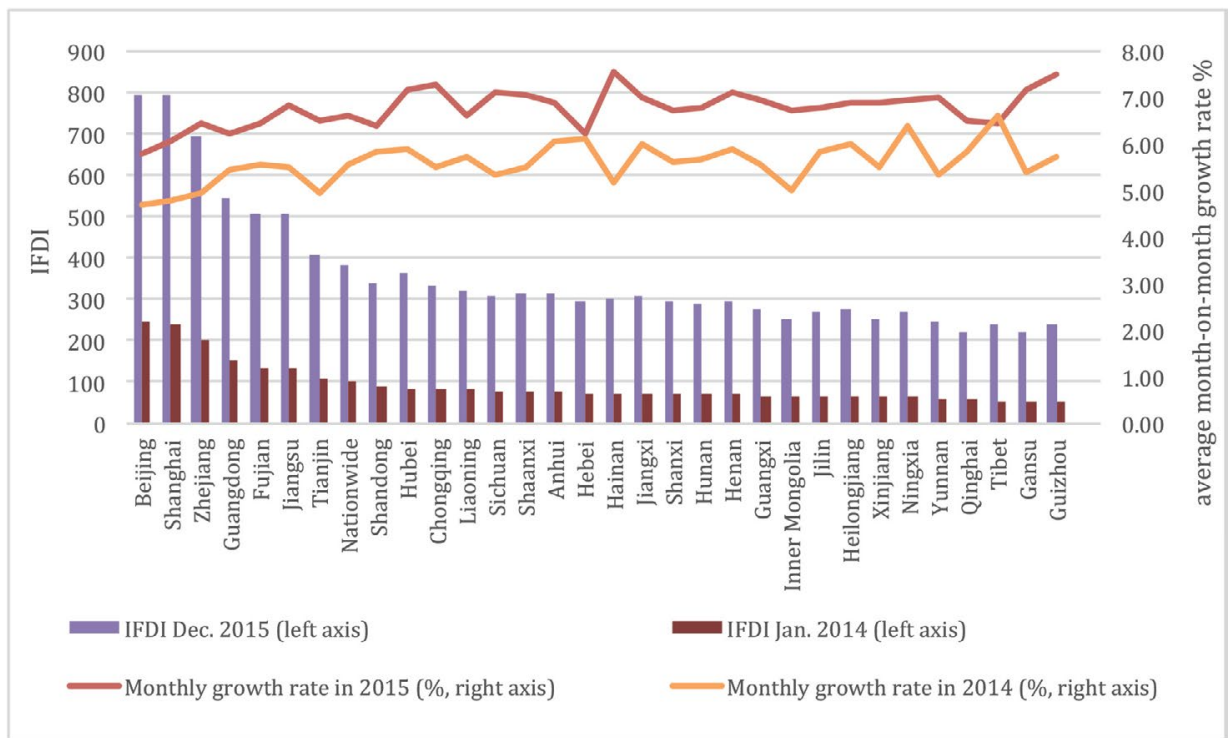

Figure 6.2 IFDI: Provincial subindices and growth, 2014-15

Source: Guo et al. (2016). 


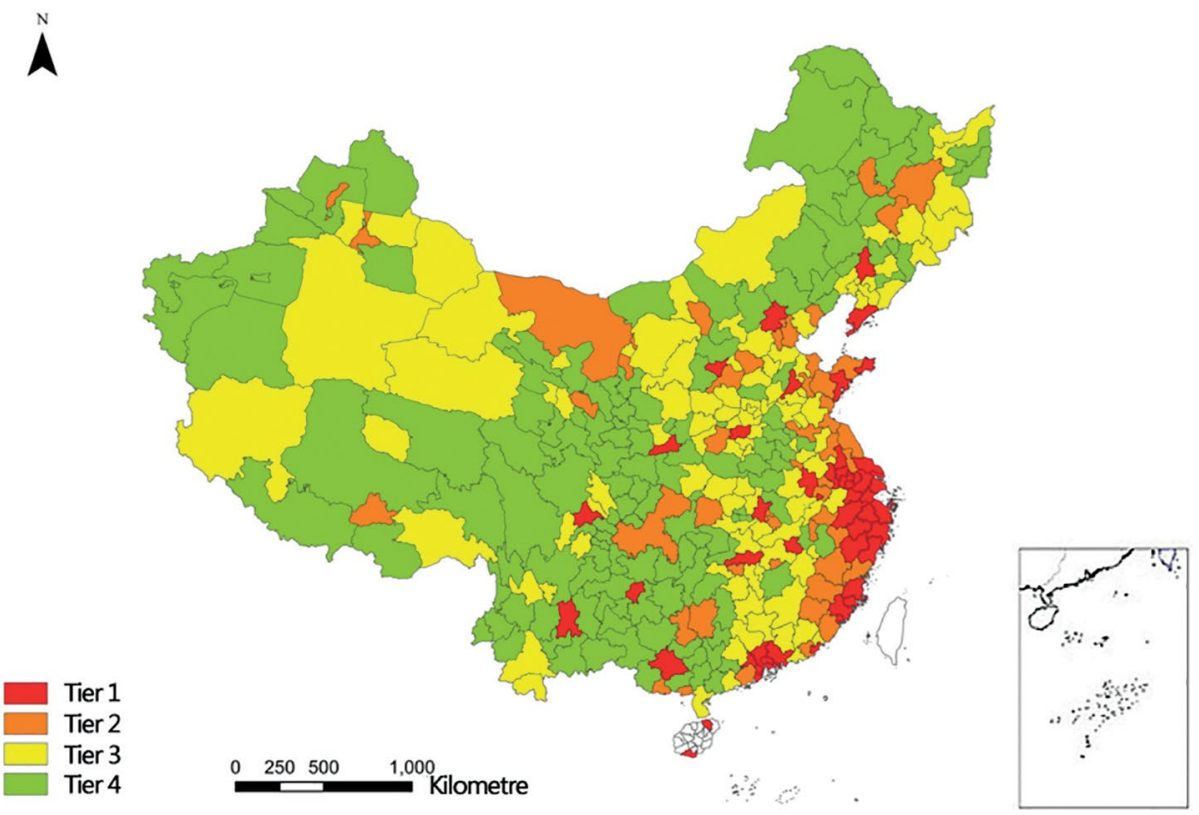

Figure 6.3 IFDI: Subindices by prefecture-level cities, December 2015 Source: Guo et al. (2016).

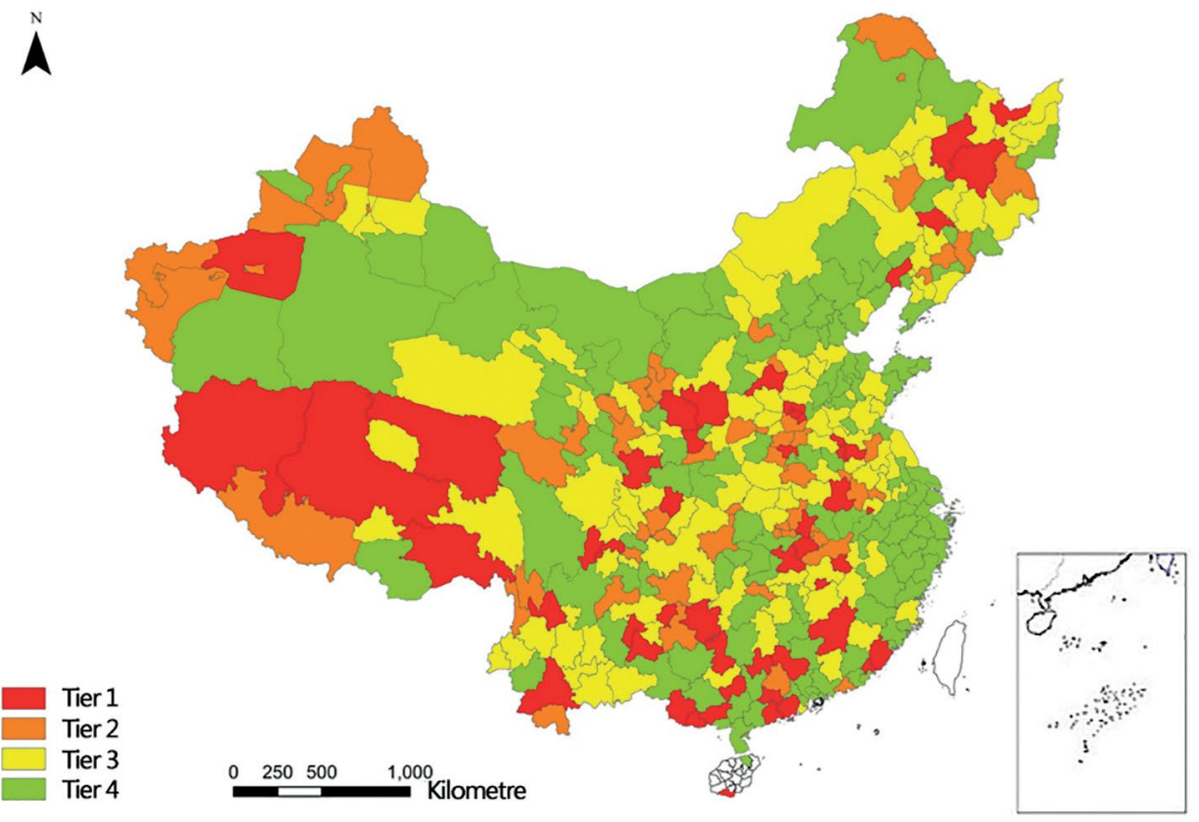

Figure 6.4 IFDI: Growth of subindices by prefecture-level cities, 2014-15

Source: Guo et al. (2016). 
Disaggregating the index to the prefecture level reveals that most cities with high IFDIs are in the eastern coastal region, especially the Yangtze River Delta and the Pearl River Delta (Figure 6.3). This is suggestive of a positive correlation between levels of internet finance and levels of economic development among cities. But the pattern is less clear for prefecture-level IFDI growth rates. In general, coastal cities also experienced relatively slower growth (Figure 6.4), a trend that is consistent with the provincial data that show coastal cities tend to be more economically developed. This is a trend that requires further empirical validation.

One interesting - and important - question concerns the relationship between internet finance and traditional finance, and the extent to which the former complements or substitutes for the latter. We use the proportion of outstanding loans from financial institutions as a share of GDP as an indicator of the development of traditional finance. By utilising prefecture-level data, we find the correlation coefficient between the stated indicator of traditional finance and IFDIs is 0.59 (Figure 6.5). We also find that higher rates of mobile phone penetration increase IFDIs at the prefecture level, with a correlation coefficient of 0.74 (Figure 6.6).

Disaggregated indices for age groups show clearly that internet finance is driven mainly by young people, especially those born in the 1980s and 1990s (Figure 6.7). Use of internet finance by those who were born in the 1990s is, in general, slightly more advanced than for those who were born in the 1980s. There is one exception, however, in that the latter group uses internet finance for investment more than the former.

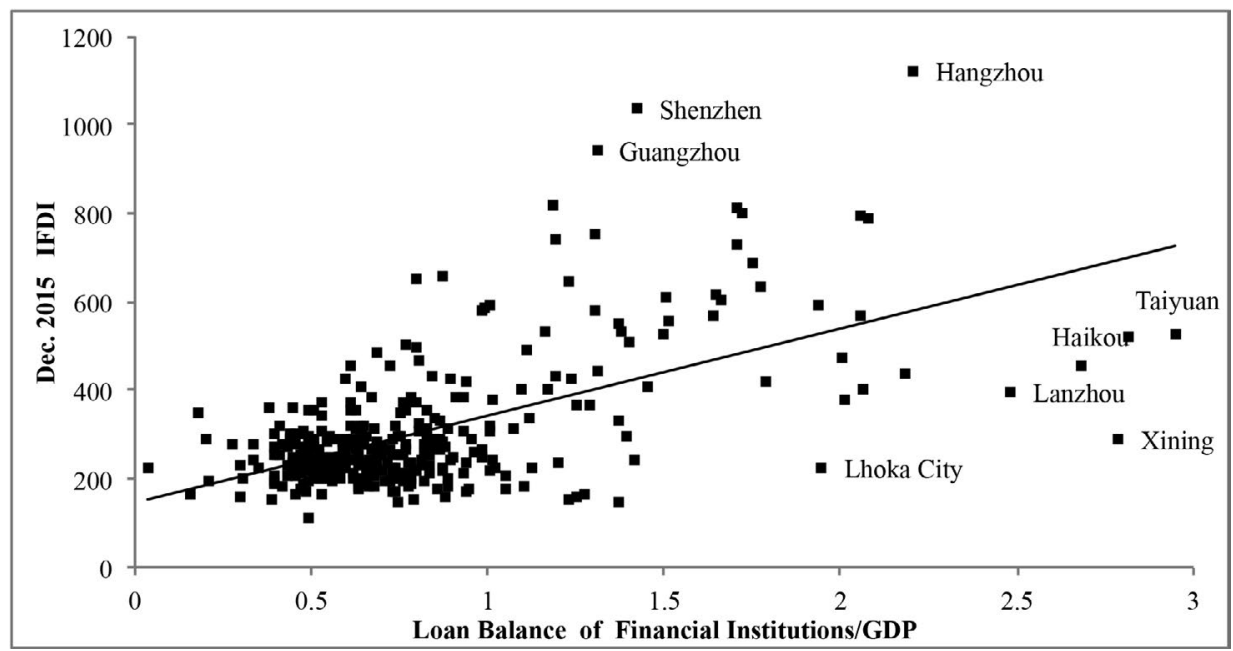

Figure 6.5 Relationship between traditional finance and IFDI at the prefecture level

Source: Guo et al. (2016). 


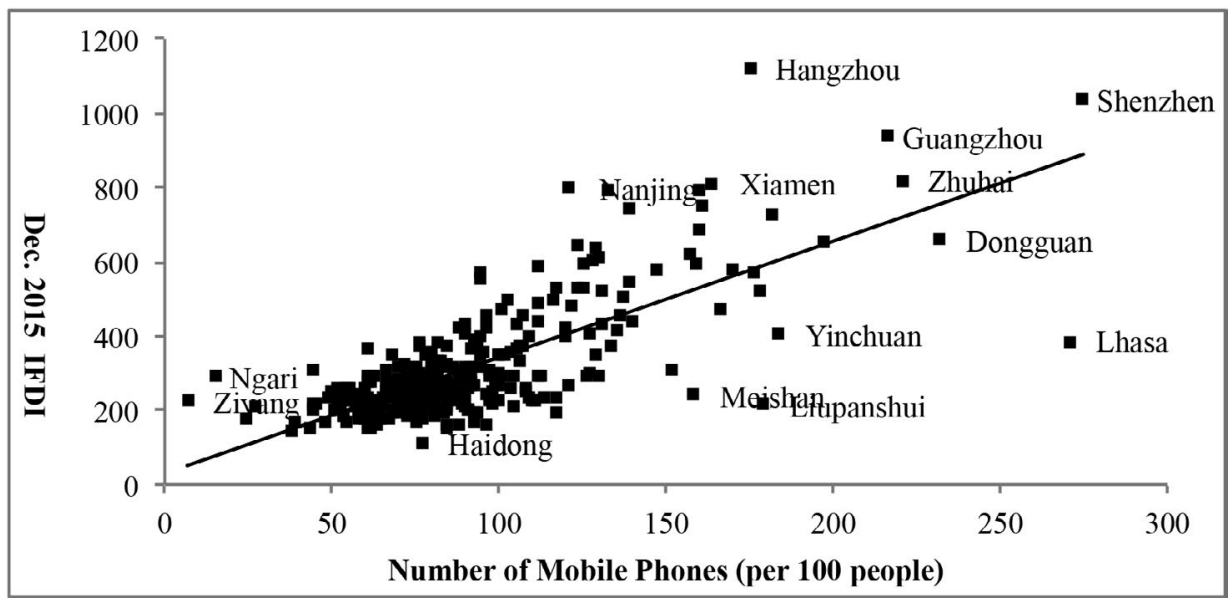

Figure 6.6 Prefecture-level relationship between mobile phone penetration and IFDI

Source: Guo et al. (2016).

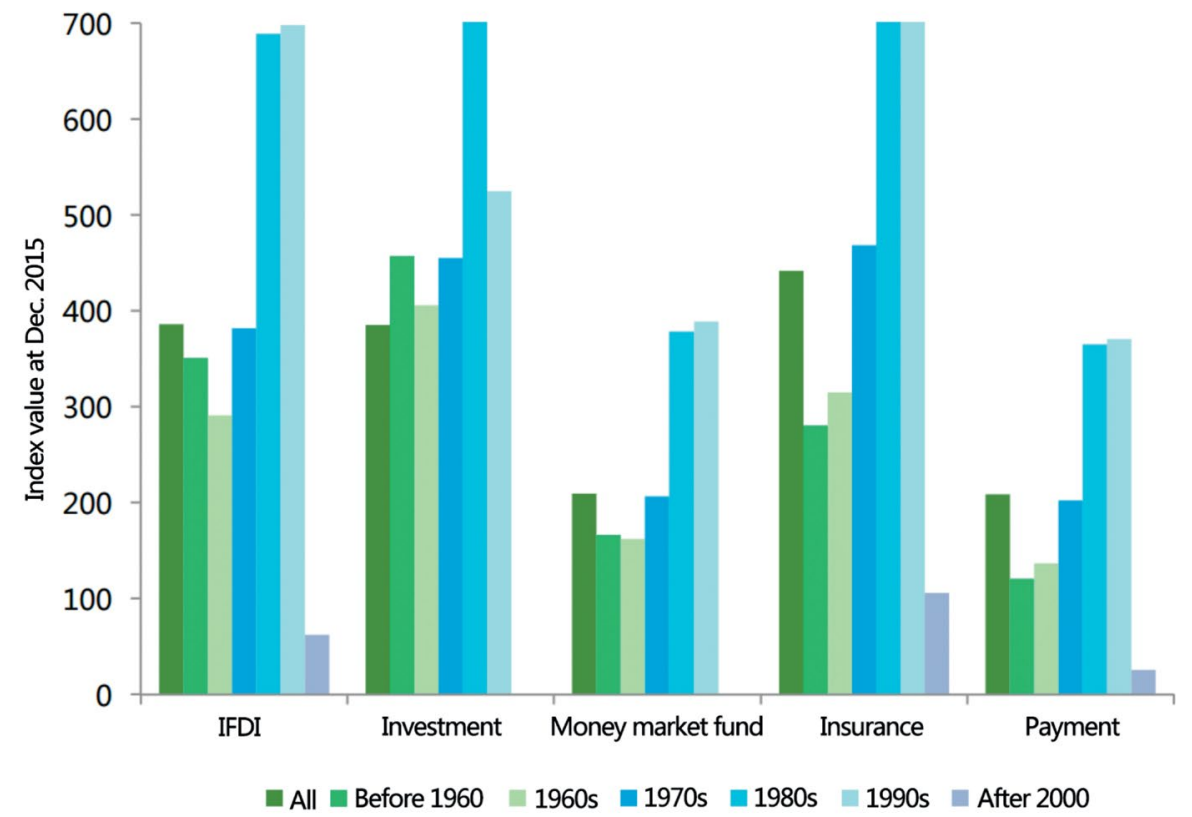

Figure 6.7 IFDI: Subindices by age group, December 2015

Source: Guo et al. (2016). 


\section{Innovation or bubble?}

Despite the rapid development of internet finance over the past several years, debate about its future never goes away. Optimists, like Ping Xie, argue that internet finance represents the third type of financial intermediation, after direct and indirect financing, and that it could completely revamp traditional financial industries. Others point out that internet finance is mainly a Chinese phenomenon and is actually a product of regulatory arbitrage, which could therefore evaporate once financial regulations tighten to levels equivalent with those in advanced economies. From mid-2015, as internet finance grew and the associated risks escalated, evidenced by growing numbers of problematic P2P lending platforms, these pessimistic assessments gained traction among financial industry practitioners, scholars and even government officials. Qilun $\mathrm{Wu}$, a famous financial commentator on Chinese microblogging website Weibo, has written an article saying P2P lending is a Ponzi scheme. A lot of people share Wu's opinion, however, they may voice it less aggressively. ${ }^{3}$ Is internet finance really just a bubble? Before jumping to conclusions, one should first understand the trends and logic underlying the boom in the sector in China.

\section{Three important factors: Light regulation, underservicing and transaction facilitation}

We see at least three important factors. The first is that regulators have adopted a light approach. Internationally, commentators have noted that it is almost impossible for trade and manufacturing companies to be granted finance-related operating licences in many countries, including the United States. In China, however, selective online shopping firms, such as Alibaba and Jingdong, and social media platforms such as Tecent have received permission to supply financial services. Without this friendly regulation, it would not have been possible for internet finance in China to reach current levels of activity.

The second factor is financial underservicing, especially with respect to SMEs and average households. In pre-reform China, there was just one monolithic financial institution: the People's Bank of China (PBC). This served as both the central bank and a commercial bank. Funds transfer and allocation were guided mainly by the central plan. Financial institutions played only a very supplementary role. The reform period of the past 38 years, however, has witnessed significant developments in and transformation of the financial sector. Modern China has a significant, relatively established financial industry with a complete set of financial institutions and very large volumes of financial assets (Huang et al. 2013).

3 Available from: weibo.com/ttarticle/p/show?id=2309403966351516530359. 
The government does, however, continue to intervene in the functioning of the financial system, as is the case in advanced countries. An International Monetary Fund index of financial repression measuring the extent of policy distortions with respect to restricting market-based movement of the interest rate, exchange rate and funds, finds that financial policy distortion in China is among the most severe globally (Abiad et al. 2008). One direct consequence is financial industry bias in favour of certain groups of (potential) customers. For instance, stateowned enterprises (SOEs) still receive proportionately greater access to bank credits and other funding thanks to ownership bias. Funding constraints are common globally for SMEs, but the problem is exaggerated in China. About 70 per cent of SMEs and probably a similar proportion of individuals do not receive decent financial services (Zhang 2014). Typically, to access finance, SMEs have to go to informal markets, where funding costs are often at least four times higher than those in the formal sector, such as from commercial banks.

Regulator tolerance of internet finance may relate to issues such as the undersupply of financial services to certain groups in China. It may be a way of testing new models of financial service provision. Development of inclusive finance has been a key policy objective of China's government for some years, and aims to improve the provision of market-based, commercially sustainable financial services to underserviced enterprises and individuals. Developing inclusive finance is, however, very difficult. Policymakers probably see hope in using the internet as a tool with which to facilitate inclusive finance. Certainly, many SMEs and low-income individuals have enthusiastically embraced new forms of internet finance, such as WeChatPay, Yu' ebao and Yirendai. For instance, since few university students are warmly welcomed by commercial banks because of their relatively low level of deposits, and also given their familiarity with mobile technologies, they have become very loyal and capable users of internet finance services.

The third factor is the extraordinary potential for internet technologies to facilitate financial transactions. In essence, the central challenge underlying any financial transaction can be summarised as information asymmetry. The most important function of financial intermediation is, therefore, risk pricing. In this sense, the reasons the financial industry discriminates against certain groups of customers and why development of inclusive finance is so difficult can be explained within a cost-benefit analysis framework. For instance, SME financing difficulty is common because they usually have fewer hard data, fewer assets to use as collateral and also a higher probability of failure. Due-diligence costs for these enterprises could be prohibitive. Many commercial banks and other financial institutions therefore find it cost ineffective to service such customers. Should they do so, the financing costs would correspondingly be prohibitively high, which might not be legal under certain regulations or could simply inhibit the SME from borrowing. 
The internet may shift these asymmetries, as it has two important features that traditional financial institutions normally do not: a mobile terminal and big data analysis. China is home to 785 million active smartphones (National Bureau of Statistics of PRC 2015). Together, these provide an effective means for internet companies or financial institutions to identify potential customers. Third-party payment services and direct sale of funds businesses are built primarily on internet connections to smartphones.

Big data analysis, if applied efficiently, can help reduce information asymmetry and also in part replace the otherwise labour-intensive due-diligence process. For instance, Ant Financial's online lending is based on data analyses from some one million shops and 300 million individual accounts on various online shopping platforms of its parent company, Alibaba. The shops' business and cash flows and individuals' spending behaviour and other habits offer reliable information about their credit risks, especially if they have been with Alibaba's platforms for several years. Through analysis of this data, Ant Financial is able to quickly and cost-effectively preapprove loan quotas for qualified shops and individuals. If the shops or individuals with preapproved loan quotas activate the application, it takes Ant Financial less than three minutes to put borrowed funds into the applicant's AliPay account. No face-to-face meeting is required (Figure 6.8).

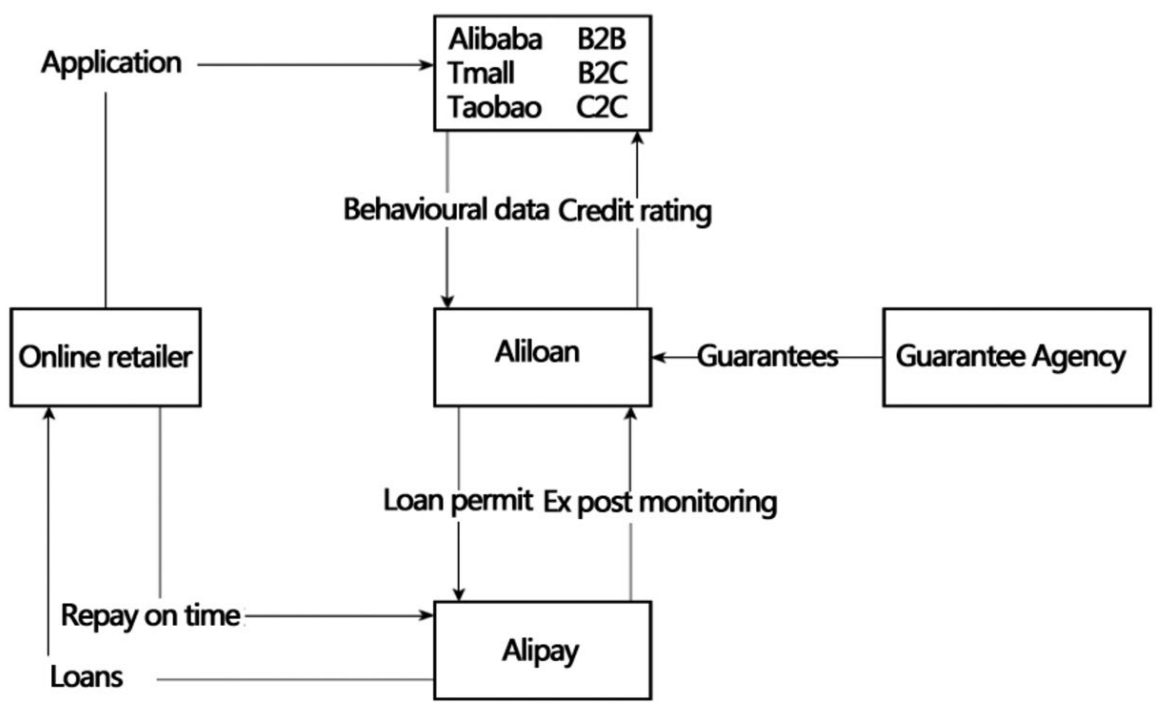

Figure 6.8 Flow chart for Ant Financial online lending

Source: Xie (2015). 
WeBank has essentially done the same thing for its service, Weilidai, except that it relies mainly on WeChat social media data. By analysing WeChat users' addresses, active chat groups, WeChatPay spending behaviour and habits of red envelope distribution during festivals (at Chinese New Year WeChatPay allows users to send electronic gifts of cash instantly using the same social media service), WeBank also preapproves individual loan quotas. If the individuals decide to activate the application, WeBank undertakes the lending in cooperation with commercial banks because, at this stage, WeBank does not have its own bank customers. To increase commercial banks' confidence in this type of risk evaluation, WeBank often contributes 20 per cent of funding for loans.

Ant Financial and WeBank assess credit risks by analysing in-house data on potential customers. Zhejiang-based Zuoli Kechuang Micro-Finance, which is a listed company on the Hong Kong Stock Exchange, also offers online loans but does not possess the same customer database. Instead, it relies on three sets of external data: 1) potential customers' main bank account transactions; 2) telephone bills with detailed call records; and 3) the PBC's personal credit information printed by a credit applicant.

In other words, a distinct advantage of internet finance over traditional finance is that it substantially reduces due-diligence costs. As a result, financial transactions that would otherwise be commercially unviable in the traditional financial industry are enabled. More importantly, the long-tail feature of internet technology implies that, once the system is established, the marginal cost of servicing additional customers is close to zero. Therefore, the internet has a natural fit with the evolution of more inclusive finance in China. In this sense, internet finance is indeed a real innovation, and not a passing bubble as some fear.

This suggests that internet finance has the potential to add real value to financial transactions, especially via enabling commercially profitable transactions from demand for credit that previously was commercially unviable. Whether this potential can turn into real business, however, is dependent on several conditions, the most critical of which is the internet's ability to continue to reduce information asymmetry for financial transactions. For internet finance to work, institutional market participants need to have sufficient understanding of finance, access to internet channels, a quality dataset and data analysis capacities. Against these straightforward criteria, we conclude that many practitioners of internet finance in China today are probably not ideally qualified. Moreover, this fact, rather than the core of the industry itself, is why the internet finance industry is suffering from bubbles and scandal at present. 


\section{Case study of P2Ps}

The development of $\mathrm{P} 2 \mathrm{P}$ lending in China has been rapid in the past several years. As shown in Table 6.1, the number of P2P platforms increased 19 times, from 200 in 2012 to 3,858 in 2015. During this same period, P2P trading volume skyrocketed from RMB21.2 billion to RMB982.8 billion, and outstanding loans surged from RMB5.6 billion to RMB547.8 billion. At the end of 2014, $\mathrm{P} 2 \mathrm{P}$ lenders in the United States generated $\$ 6.6$ billion in loans, and in Europe this number was $\$ 3.9$ billion (BI Intelligence 2015; Wardrop et al. 2015). In comparison, Chinese P2P lenders generated $\$ 41.3$ billion. In other words, China already has the world's largest P2P industry in terms of trading volume.

Even though the P2P industry remains tiny compared with formal banking balances (RMB93.95 trillion at the end of 2015), it nonetheless affects a large number of investors and borrowers. In April 2016, P2P platforms in China had 2.98 million active investors and 800,000 borrowers (Table 6.1, columns 6 and 7). Therefore, the sharply increased number of financial collapses of $\mathrm{P} 2 \mathrm{P}$ platforms has generated great concern among the general public. Specifically, the number of problematic P2P platforms skyrocketed from 16 in 2012 to 1,598 in April 2016 (Table 6.1, column 3). In other words, some 40 per cent (1,598 of $4,029)$ of $\mathrm{P} 2 \mathrm{P}$ platforms were problematic in 2016. A platform is identified as problematic if it records at least one of the following difficulties: termination of operation, failure to cash out, cheating, loss of contact, police interference or platform shutdown.

Table 6.1 Chinese P2P platforms at a glance

\begin{tabular}{|c|c|c|c|c|c|c|}
\hline \multirow[t]{2}{*}{ (1) Year } & \multicolumn{2}{|c|}{ Platforms } & \multirow{2}{*}{$\begin{array}{l}\text { (4) Trading } \\
\text { Vol (Billion) }\end{array}$} & \multirow{2}{*}{$\begin{array}{l}\text { (5) Balance } \\
\text { (Billion) }\end{array}$} & \multirow{2}{*}{$\begin{array}{c}\text { (6) } \\
\text { Investors } \\
\text { (Thousand) }\end{array}$} & \multirow{2}{*}{$\begin{array}{c}\text { (7) } \\
\text { Borrowers } \\
\text { (Thousand) }\end{array}$} \\
\hline & (2) All & (3) Problem & & & & \\
\hline 2012 & 200 & 16 & 21.2 & 5.6 & 51 & 19 \\
\hline 2013 & 800 & 92 & 105.8 & 26.8 & 250 & 150 \\
\hline 2014 & 1,575 & 367 & 252.8 & 103.6 & 1,160 & 630 \\
\hline 2015 & 3,858 & 1,263 & 982.3 & 439.5 & 2,980 & 780 \\
\hline $2016^{*}$ & 4,029 & 1,598 & 522.8 & 547.8 & 2,980 & 800 \\
\hline
\end{tabular}

* Data for 2016 cover January-April only. Source: wdzj.com/. 
On the other hand, P2P lending in China does provide room for investors to reap higher returns and for borrowers to access funds at lower costs. In Figure 6.9, we compare several interest rates in China, with 'P2P lending' denoting the composite investors' interest rates in all P2P platforms. After earlier oscillations, the P2P investor interest rate decreased from above 20 per cent in 2013 to about 10 per cent at the end of 2015. Compared with returns from an online investment fund like Yu'ebao, the one-week Shanghai Interbank Offered Rate (Shibor) and the three-month bill rate from the $\mathrm{PBC}$, which all fluctuated around 5 per cent, P2P platforms appear to provide investors a higher return. For borrowers, this compares favourably with the 20 per cent lending rate charged for informal finance (Wenzhou private lending in Figure 6.9).

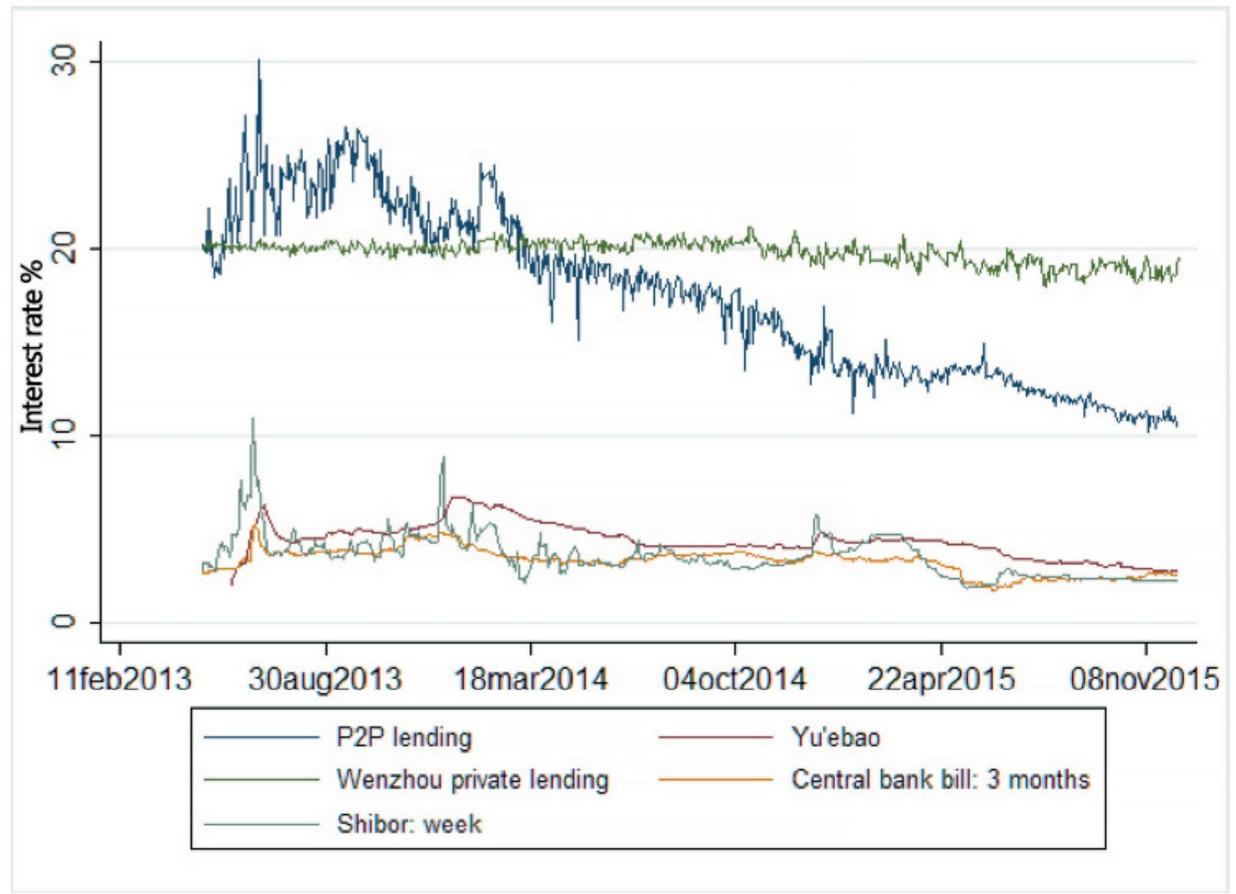

Figure 6.9 Comparison of P2P composite interest rates with others

Notes: P2P lending = the composite investors' interest rates in all P2P platforms; Yu'ebao = online investment fund rate managed by Alibaba; WenZhou private lending = a representative lending rate of informal finance in China; Central Bank bill three months = rate of three-month bill from PBC; Shibor = weekly Shanghai Interbank Offered Rate.

Source: Huang et al. (2016).

Given that the development of $\mathrm{P} 2 \mathrm{P}$ lending has so far expedited financial innovation, increased capital allocation efficiency and encouraged competition, for some years China's regulators have taken a lenient stance towards the industry. In fact, it has so far been unclear which regulatory authority should be responsible for $\mathrm{P} 2 \mathrm{P}$ platforms. The first official document relating to the 
industry, 'Guidance on promoting the healthy development of internet banking', was released only in July 2015. This designated the China Banking Regulatory Commission (CBRC) as the main regulatory authority. On 28 December 2015, the regulatory authorities revealed a draft of proposed rules for regulating the P2P industry. The announcement compels online lenders to act as information intermediaries only and not as credit intermediaries, and also prohibits leveraged outside funding. On the other hand, no minimum registered capital was stipulated. Local financial authorities will be the main regulating authority and are expected to both register and supervise P2P lenders. Under this type of regulatory scheme, $\mathrm{P} 2 \mathrm{P}$ platforms will not need to hold a special licence and there will be no specific requirements on deposits or management of funds. Supervision will rely on organisations such as micro-loan associations.

Some might question whether the $\mathrm{P} 2 \mathrm{P}$ industry will prosper or go astray amid such a light regulatory scheme characterised by no licensing requirements, no minimum entrance requirements and with industry associations as the main regulatory authority. To shed light on this uncertainty, we use all publicly available P2P platform-level data to study the characteristics of problematic platforms and to identify the risk factors of this industry.

Using a big-data approach, we extract and integrate all publicly available P2P platform datasets from the four major P2P information platforms up to the end of 2015. After cleaning the outliers and crosschecking, we obtained a dataset of 3,439 P2P platforms with registered capital, among which there are 1,048 problematic platforms. Data points collected include establishment date, registered capital, date the platform became problematic, the nature or type of problems, whether or not a platform has a guaranteed investor, the structure of the loan term, investor interest rate, projects in which the platform has invested, location, whether the platform offers customer service, VIP (very important person) services, toll-free call services and so on. As all the data were collected on 8 December 2015, the life of some platforms may be curtailed. In other words, when we observe a life of 30 days in the data, it could be for two reasons: one is the platform stayed active for only 30 days, from the date it first went online until the day it became problematic; two, it was online on 8 November 2015, active on 8 December 2015 and we do not know how long it will survive. Our estimation method needs to deal carefully with this issue. We therefore use the Kaplan-Meier nonparametric estimator to study the survival probabilities of the various platforms with different perspectives, and then use duration estimation to consider all risk factors together.

Our analyses unveil a number of important findings:

- First, problematic platforms survive for an increasingly short duration. In Figure 6.10, we compare the survival durations of normal platforms and problematic platforms. Overall, 18 per cent of the 192 problematic platforms 
survived for less than 30 days; 55 per cent lasted less than half a year; and over 80 per cent stayed in the industry for less than a year. In contrast, over 38 per cent $([979+215+118] / 3,439)$ of normal platforms survived for more than one year and over 60 per cent lasted more than half a year. In particular, our duration analysis indicates that compared with platforms established before 2012, on average, more recently established platforms have shorter lives and suffer a higher probability of becoming problematic platforms.

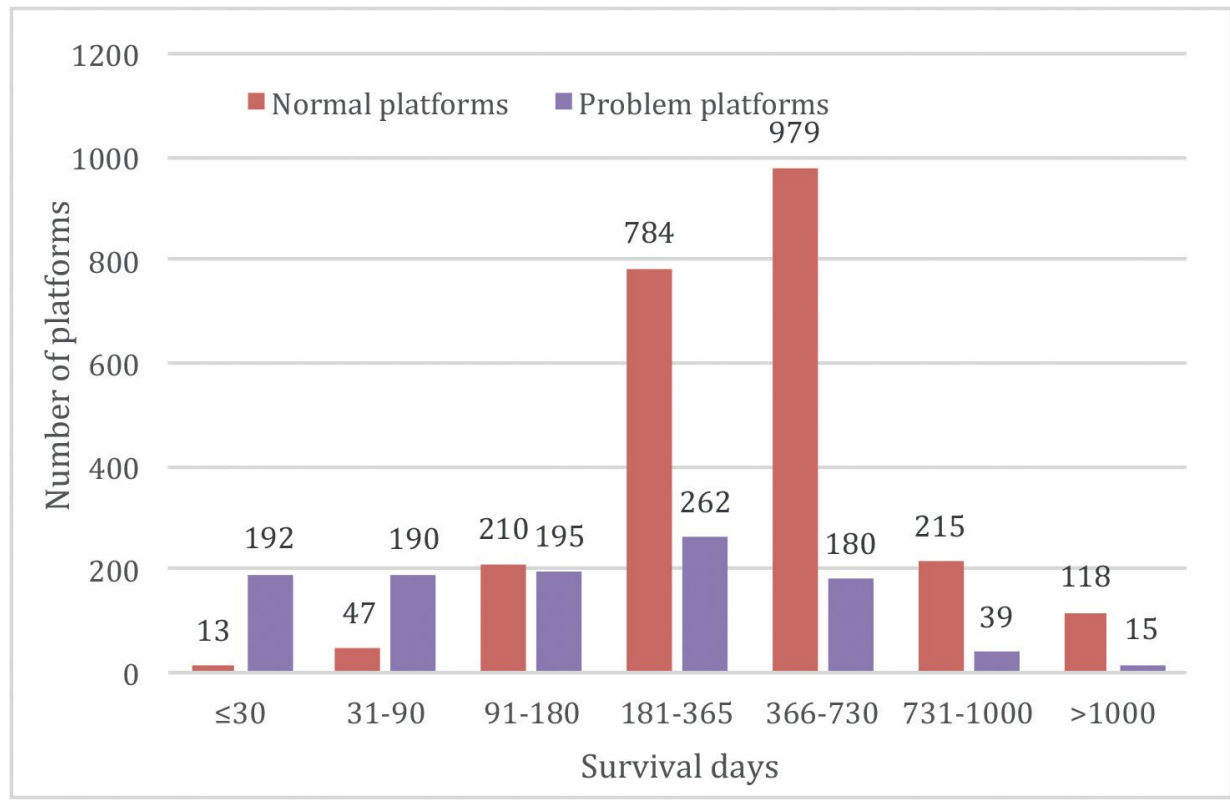

Figure 6.10 Average number of operating days of normal platforms and problematic platforms

Source: Huang et al. (2016).

- Second, problematic platforms are not concentrated in particular regions. If one studies only Figure 6.11a, where darker regions indicate the presence of more problematic platforms, it is easy to conclude that problematic platforms are concentrated in coastal areas, and especially in the provinces of Shandong, Guangdong and Fujian. Taking into account the fact that coastal regions have more platforms than inland areas, from Figure $6.11 \mathrm{~b}$, one can infer that there is no particular regional pattern in problematic platform distribution. This is consistent with the characteristics of internet finance; as transactions are operated through the internet, regional differences will be smaller than for enterprises focusing their business in local areas. So the distribution of problematic platforms should be studied together with their relative share among all platforms. 


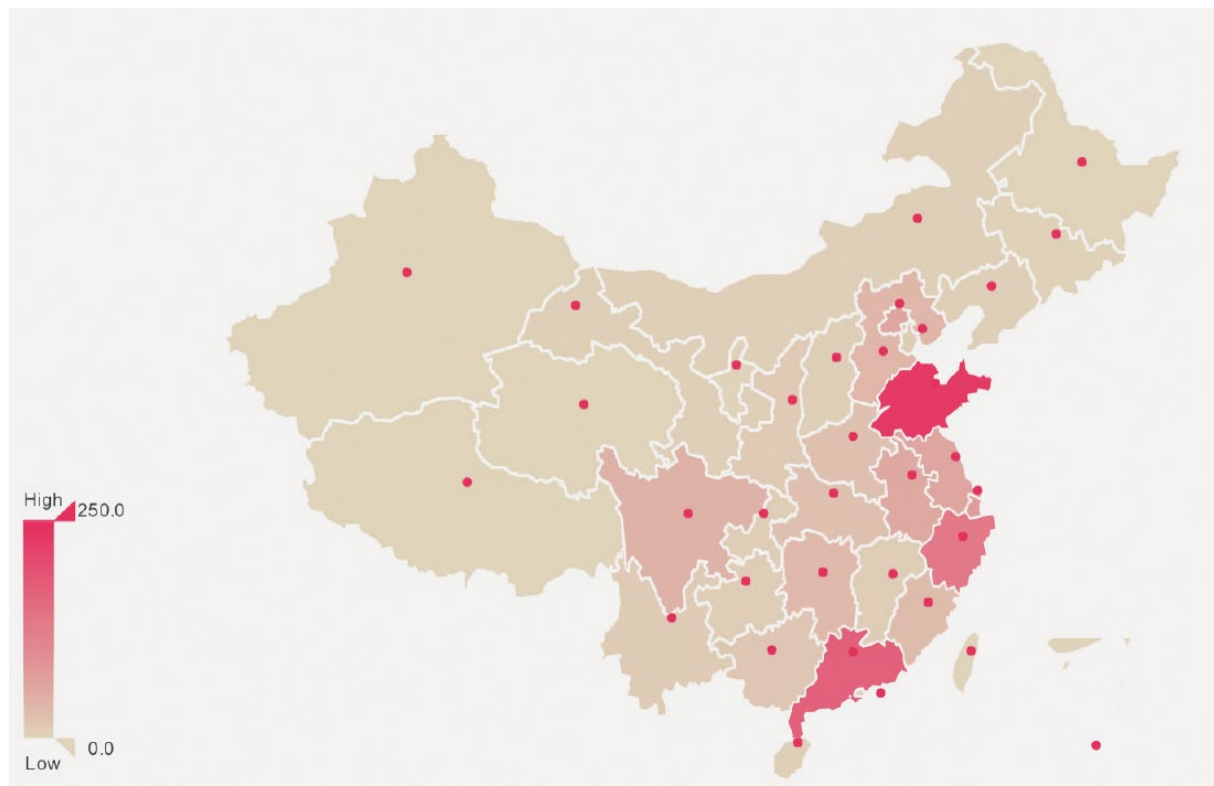

Figure 6.11a Regional distribution of all problematic P2P platforms

Source: Huang et al. (2016).
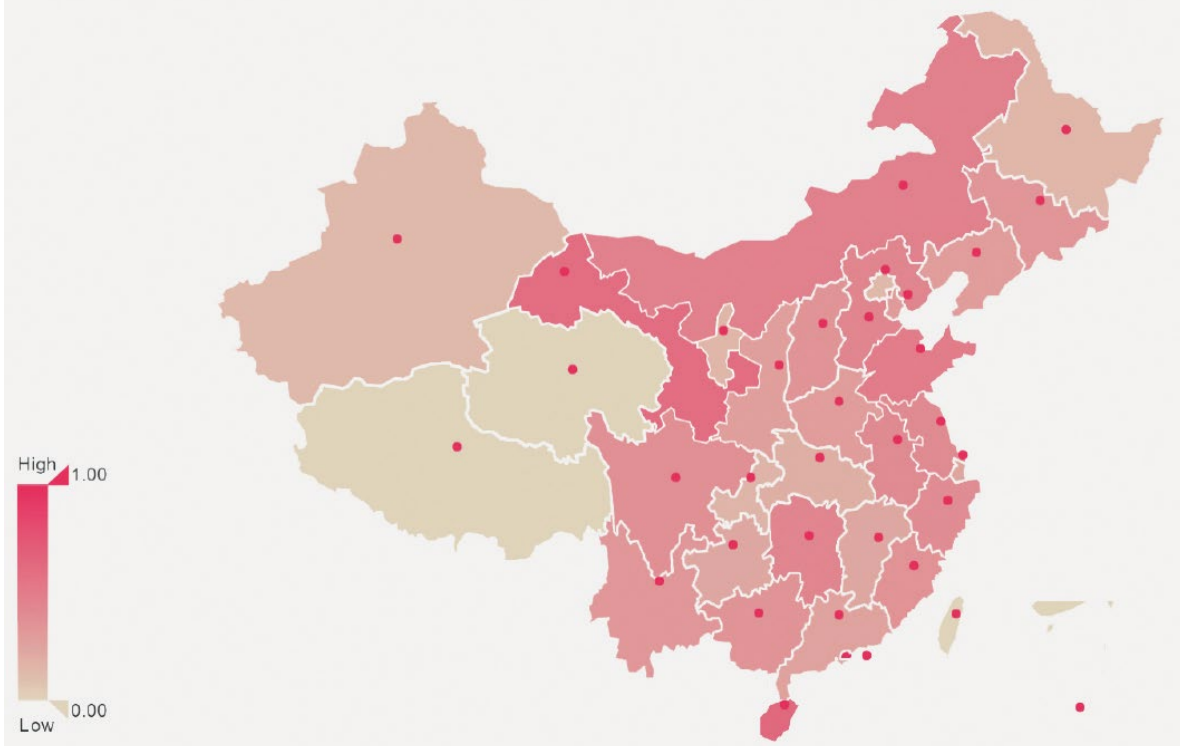

Figure 6.11b Regional distribution of proportions of problematic platforms

Source: Huang et al. (2016). 
- Third, missing information on registered capital or low registered capital signifies a high platform risk. Figure 6.12 compares the survival probabilities of three platform types: those missing registered capital, those with less than RMB30 million in registered capital and those with more than RMB30 million in registered capital. The horizontal axis shows the survival days and the vertical axis shows the probability. Platforms missing registered information are highly risky, as demonstrated by the sharp drop in their 200day survival probability, to around 25 per cent. In other words, given four newly established platforms, three will not survive more than 200 days if they are missing information on registered capital. Platforms with less registered capital also tend towards a lower survival probability. One-fifth of platforms with more than RMB30 million in registered capital are problematic, but this ratio drops to 37.2 per cent for platforms with less than 30 million. Similarly, platforms missing actual capital information or with a low ratio of actual capital to registered capital have lower survival probabilities.

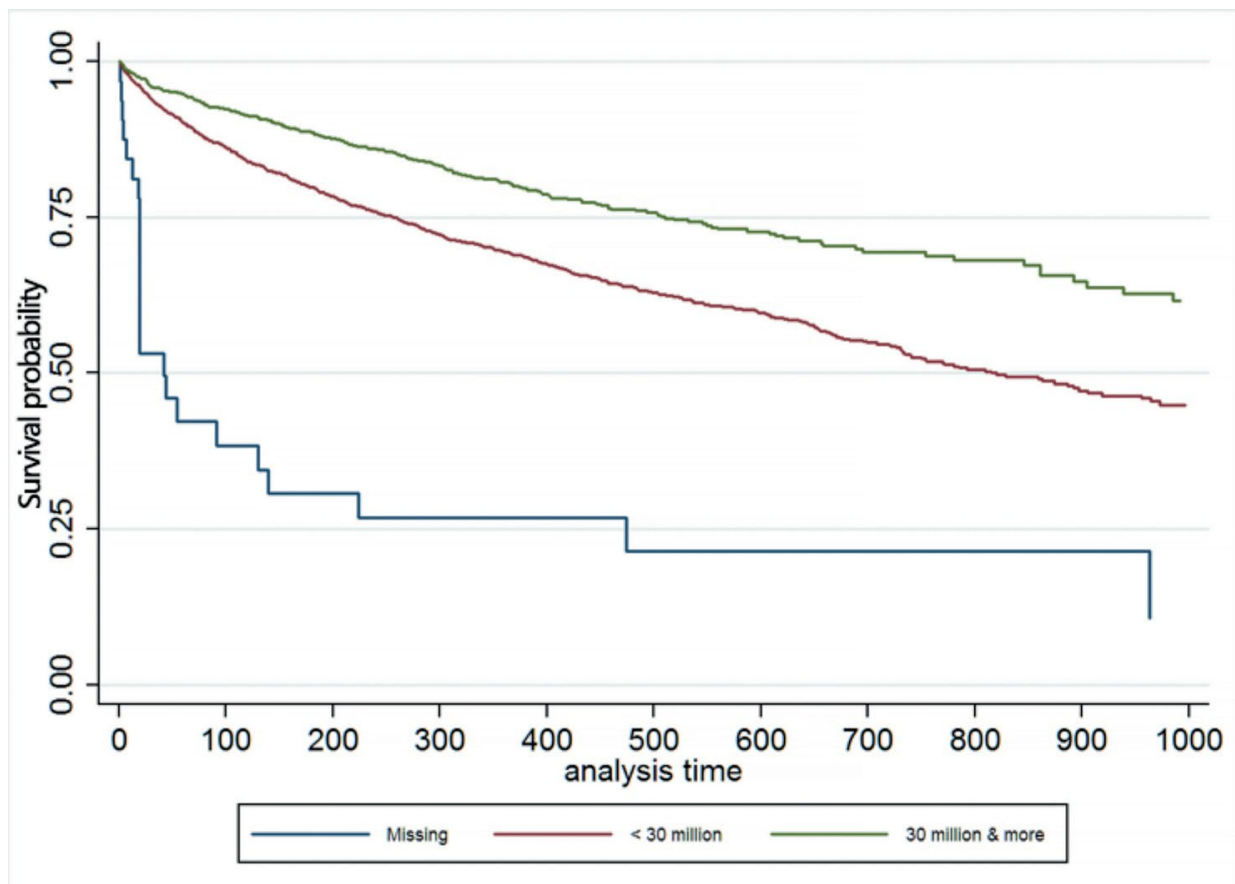

Figure 6.12 Survival probability and registered capital

Source: Huang et al. (2016).

- Fourth, highly risky platforms are often missing interest rate information, have a narrow transaction interest rate range or offer unusually high or low interest rates. Of the problematic platforms, 77.5 per cent are missing information on investor interest rates. If a platform 
offers only one interest rate, it is highly likely to be a problematic platform. It is no surprise that problematic platforms have demonstrated higher probabilities to promise investors interest rates higher than 20 per cent. In Figure 6.13, however, we show that platforms offering rates of less than 8 per cent are also highly risky. Some 60 per cent of problematic platforms offer interest rates lower than 8 per cent. For example, in 2015, the Ezu Bao platform was charged with illegally raising about $\$ 7.6$ billion in funds. The data show that Ezu Bao did offer an interest rate of 6 per cent for some of its financial leasing projects before the crackdown. As investors can easily buy wealth management products with an annual return of less than 8 per cent, when P2P platforms offer such interest it is highly likely the transactions that ensue are fake and hence the platform bears high risk. Similarly, platforms offering only one interest rate are dubious.

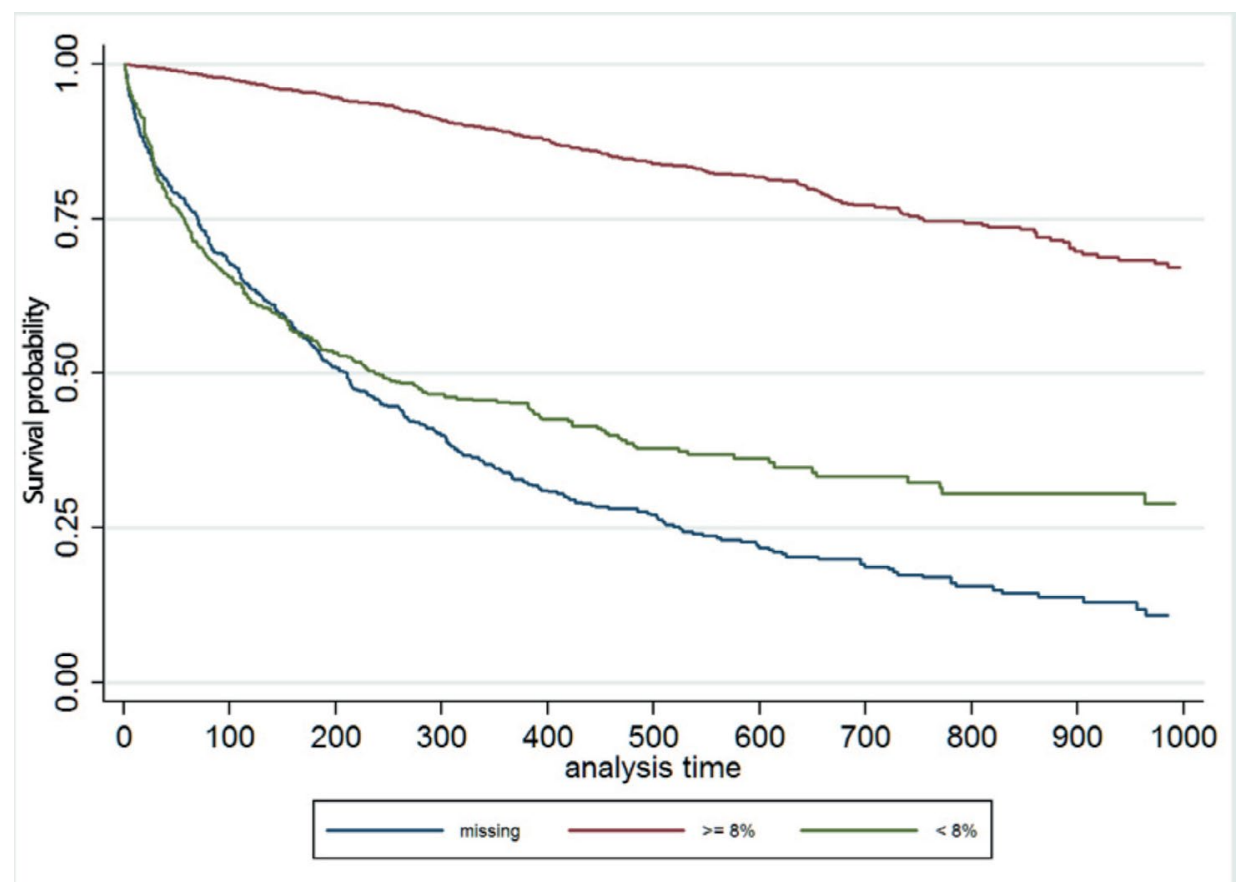

Figure 6.13 Survival probabilities for platforms with interest rates lower or higher than 8 per cent

Source: Huang et al. (2016).

- Fifth, platforms without reliable third-party assurance are highly risky. What matters for the reliability of a platform is not how many types of assurance it has, but whether it is assured by a reliable insurance company or bank. For those with (without) such assurances, 3 per cent (14 per cent) is the problematic threshold. 
- Finally, platforms guaranteeing both principal and return are highly risky. If a platform promises its investors that both the principal and the interest are 100 per cent secured, its probability of being a problematic platform is 20.7 per cent - a rate that is 12 per cent higher than for firms not offering such promises. Such guarantees will, naturally, increase a P2P platform's costs. There may also be an adverse selection issue - that is, platforms that are having financial difficulties and that are desperate for funds tend to be the ones providing investors such offers, which are unsustainable in the long run.

The above findings are important for understanding the risks associated with P2P platforms. Investors, for example, should stay away from risky platforms and realise that platforms are less risky when they have a longer survival time, adopt a strategy for complete information disclosure, provide appropriate interest rates, maintain diversified interest rate term structures and have acquired assurances from banks or insurance companies. An investor should avoid platforms missing key information such as registered capital, interest rates and term structure, and promising full guarantees towards both principal and interest.

\section{Implications for regulation}

Our review and analysis reveal two important features of the development of internet finance in China. First, it fills an important gap in the market by extending financial services to customers who are insufficiently serviced by the traditional financial industry. Second, it also facilitates financial transactions in general by lowering costs and reducing risks through better use of customer analytics data-by reducing information asymmetry. On these two counts, we see that internet finance offers genuine innovation. If these features can be further improved and strengthened, internet finance should survive, especially as a form of more inclusive finance, whether or not regulations are tightened significantly. It is in fact even possible that China is leading a new product cycle globally in this pioneering area.

As with any young but promising new industry, the risks are high for China's internet finance sector. Many investors, for example, chase quick money through either blind optimism or Ponzi schemes. At the end of the twentieth century, the United States also experienced a collapse of its internet bubble, but there was real and lasting innovation: a number of global leaders such as Google and Amazon rose from the ashes. At this stage, there are no guarantees that internet finance will even survive, as was the case with selective internet-based IT platforms 15 years ago. 
To ensure healthy development of internet finance, important conditions need to be met in at least three areas. The first requires there to be a set of 'infrastructure' facilities. At the minimum, this requires a network of mobile terminals or the ability to analyse available data, or both. Strictly speaking, big data still does not exist in China. The government may need to introduce a policy framework to both make useful data publicly accessible and safeguard individuals' privacy. A credible and integrated credit reporting system for individuals and SMEs would also be valuable for internet finance credit allocation decisions.

The second condition concerns regulation of financial qualifications for industry participants. At the moment, there are three groups of professionals working in this sector: financial professionals, IT experts and others. The essence of internet finance is the financial transaction. Therefore, it is vital for internet finance professionals to have a good understanding of finance, especially the related risks. According to our limited observations, a lot of problems in the internet finance sector were created by professionals who did not understand or respect basic financial rules and principles.

The third condition relates to a regulatory framework that strikes a balance between encouraging innovation and controlling risks. Internet finance is finance, and financial transactions need to be appropriately regulated. Both too little and too much regulation could hinder the otherwise beneficial evolution of internet finance.

Here we make a preliminary assessment of the regulatory framework for $\mathrm{P} 2 \mathrm{P}$ proposed by the CBRC in December 2015, which itself was based largely on analytical findings for problematic P2P platforms described in section four. The first relates to the macro side of managing the dynamic emergence of new internet-based informal lending agencies. The second relates to the micro side of these institutions, and ensuring they have the necessary qualifications and systems to take appropriate risk controls.

On the first point, at the baseline, the credit reporting system is at an early stage of development and social trust remains low in China. In this environment, the merit of treating the $\mathrm{P} 2 \mathrm{P}$ platform as a pure information intermediary in China has not yet been ascertained. As information intermediaries, P2P platforms should not engage in activities appropriate to credit intermediaries. However, the majority of borrowers in P2P platforms are individuals and SMEs, and the majority of investors are individuals. In fact, most internet finance platforms are not capable of providing sufficient and accurate information to help investors make investment decisions, and they are therefore de facto credit intermediaries. As long as the credit reporting system is not significantly improved there will be no change to this situation, even if all platforms changed their names to include 'information intermediary' after the requirements of the regulatory 
authority. Moreover, if regulatory authorities insist that P2P platforms should be information intermediaries, they will have to enforce one of two alternative strategies. The first would be to crack down on all platforms that are not information intermediaries, which would in effect terminate the industry; the second would be to tolerate a majority of these platforms undertaking what are illegal transactions until a substantial financial collapse makes the headlines, after which it would be relatively easy and necessary to impose legal constraints on the industry.

Second, since most $\mathrm{P} 2 \mathrm{P}$ lending platforms are not qualified information intermediaries and such platforms are numerous, it may not be deemed appropriate to implement a framework of no minimum capital requirements, only requiring platforms to register with local regulatory authorities and to be supervised by organisations like industrial associations. On the other hand, if it remains obvious that regulation will not check the qualifications of those operating a P2P business, most platforms will simply continue to operate until they become problematic.

Data from the first four months of 2016 show that risks in the internet finance industry appear to be increasing, despite the announcement of a draft regulatory scheme announced in December 2015. Huang et al. (2016) identified that more recent platforms have higher failure probabilities. Besides bad platform management, the advance of more prominent platforms and apparent promises of returns may have tempted others to engage in Ponzi scams. While some of these scams will be uncovered and legal action taken, the losses for investors are often hard to recover. Given these potential losses, it would be inappropriate to treat such situations as opportunities to educate investors, as the P2P industry is not like the capital market. That is, it does not have an established and complete regulatory framework on cooperative governance, transaction conditions and information disclosure. From this perspective, a strategy of not taking preventative regulatory action against perceivable and probable losses is hard to justify to the general public.

Third, what consequences will investors bear if local financial authorities become the major regulators? Such arrangements govern micro-loan companies; however, P2P platforms are different from micro-loan companies in several aspects. First, micro-loan companies typically do not operate across regions, but P2P platforms, operating through the internet, commonly execute transactions across multiple regions. Figure 6.3 indicates that problematic platforms show no region-specific patterns. In addition, when disputes between platforms and investors need to be tackled via legal channels, if the plaintiffs are scattered across provinces, the internet platforms will need to go through the courts in a series of different provinces. Second, the sources of funds for formal microloan companies are the capital and donations of their shareholders, and funds 
are often from no more than two banks. In contrast, for $\mathrm{P} 2 \mathrm{P}$ platforms, the majority of investors are individuals with potentially inadequate financial education to appreciate the risks they are taking, individually or systemically. The interactions of internet and individual investors could potentially rapidly propagate risks to a much larger scale. Further, local financial offices may not have the appropriate equipment, knowledge or sufficient resources to effectively regulate platforms within their jurisdiction.

If a consensus can be reached from this analysis, it is to recommend authorities revise the internet finance regulations in the following areas. First, we suggest the CBRC be made responsible for the formulation, coordination and implementation of related regulatory policies. Second, minimum qualification requirements for P2P platforms should be specified - for example, there should be a threshold of registered capital for new P2P entrants. Such requirements will not contradict the policy of encouraging financial innovation, but will offer a necessary check to protect vulnerable investors. It would also help the industry grow in a healthy direction by restricting the entrance of unqualified platforms into the market. Even where such platforms are considered as information intermediaries, there should still be requirements regarding registered capital and platforms should be supervised as to whether actual capital is injected over time. If internet finance platforms are considered credit intermediaries, higher capital standards should be set. The regulatory framework should also prohibit certain transactions and set up rules that regulate borrowing qualifications, project types, loan term structure, interest rate ranges and so on. Third, strict information disclosure rules should be established. For platforms unable to provide key information, or failing to update information in a timely manner, the authorities should limit their operations or revoke their operational eligibility.

\section{References}

Abiad, A., Detragiache, E. and Tressel, T. (2008), A new database of financial reforms, No. 2008-2266, Washington, DC: International Monetary Fund.

BI Intelligence (2015), Peer-to-peer lending markets: The leading countries for alternative finance and the next high-growth markets, Business Insider, 16 May.

Guo, F., Kong, S., Wang, J., Cheng, A., Yuan, F., Shao, G., Wang, F. and Yang, J. (2016), Peking University internet finance development index, May, Institute of Internet Finance, Beijing: Peking University.

Huang, Y., Shen, Y. and Wang, J. (2016), Analyses and thoughts on individual online lending and its regulatory framework, [in Chinese], Comparative Studies, 2(2016). 
Huang, Y., Wang, X., Wang, B. and Lin, N. (2013), Financial reform in China: Progress and challenges, in Y. C. Park and H. Patrick (eds), How finance is shaping the economies of China, Japan, and Korea, 44-142, New York: Columbia University Press.

National Bureau of Statistics of PRC (2015), Statistical Communiqué of the People's Republic of China on the 2015 National Economic and Social Development.

Wardrop, R., Zhang, B., Rau, R. and Gray, M. (2015), Moving mainstream: The European alternative finance benchmarking report, Cambridge: University of Cambridge.

Xie, P. (2015), Fundamental theory of internet finance, Lecture notes, November, Institute of Internet Finance, Peking University, Beijing.

Xie, P. and Zou, C. (2012), Research on business models of internet finance, [in Chinese], Financial Research, (12).

Xie, P., Zou, C. and Liu, H. (2014), Handbook of internet finance, Beijing: Renmin University Press.

Zhang, W. (2014), Study on Chinese commercial bank credit financing problem on small and micro enterprises, [in Chinese], Doctoral dissertation, University of International Business and Economics, Beijing. 
This text is taken from China's New Sources of Economic Growth: Reform, resources and climate change, Volume 1, edited by Ligang Song, Ross Garnaut, Cai Fang \& Lauren Johnston, published 2016 by ANU Press, The Australian National University, Canberra, Australia. 